\title{
Enhanced Photogenerated Electron Transfer in a Semi-artificial Photosynthesis System based on Highly Dispersed Titanium Oxide Nanoparticles
}

Xiaoqin Pan, ${ }^{a, b}$ Dongna Li, ${ }^{b}$ Yueping Fang, ${ }^{b}$ Zhihao Liang, ${ }^{a}$ Haoran Zhang, ${ }^{b, c}$ Jin Zhong Zhang, ${ }^{d}$ Bingfu Lei, ${ }^{* a, b, c}$ and Shiwei Song ${ }^{* a}$

${ }^{a}$ College of Horticulture, South China Agricultural University, Guangzhou 510642, P. R. China. ${ }^{\mathrm{b}}$ Guangdong Provincial Engineering Technology Research Center for Optical Agriculture, College of Materials and Energy, South China Agricultural University, Guangzhou 510642, P. R. China

${ }^{\mathrm{c}}$ Guangdong Laboratory of Lingnan Mordern Agriculture, Guangzhou 510642, P. R. China

${ }^{\mathrm{d}}$ Department of Chemistry \& Biochemistry, University of California, Santa Cruz, CA 94720, USA

"Corresponding author: E-mail address: tleibf@scau.edu.cn (B. Lei), swsong@scau.edu.cn (S. Song). 


\section{Experimental}

\section{Materials}

Tetrabutyl titanate $\left(\mathrm{Ti}\left(\mathrm{OC}_{4} \mathrm{H}_{9}\right)_{4}, 99 \%\right)$, ethanol absolute $\left(\mathrm{CH}_{3} \mathrm{CH}_{2} \mathrm{OH}, 99 \%\right)$, cyclohexane

$\left(\mathrm{C}_{6} \mathrm{H}_{12}\right)$, hydrochloric acid $(\mathrm{HCl}, 36-38 \%)$, methylene blue (MB), 2,6-dichlorophenolindophenol (DCPIP), sucrose, potassium chloride $(\mathrm{KCl})$, dibasic sodium phosphate $\left(\mathrm{Na}_{2} \mathrm{HPO}_{4}\right)$, potassium phosphate monobasic $\left(\mathrm{KH}_{2} \mathrm{PO}_{4}\right)$, and acetone were purchased from MACLIN.

\section{Synthesis of nanoTiO}

According to Liu et al., ${ }^{1} 36 \mathrm{~mL} \mathrm{Ti}\left(\mathrm{OC}_{4} \mathrm{H}_{9}\right)_{4}$ was mixed with $90 \mathrm{~mL}$ ethanol and $90 \mathrm{~mL} \mathrm{C}_{6} \mathrm{H}_{12}$ for $10 \mathrm{~min}$. Then, $9.0 \mathrm{~mL} \mathrm{36 \%} \mathrm{HCl}$ was added and mixed for $10 \mathrm{~min}$. The mixture was placed into a $70{ }^{\circ} \mathrm{C}$ water bath and stirred refluxing for $10 \mathrm{~h}$. After cooling to room temperature, $600 \mathrm{~mL}$ ethanol was mixed dropwise in $2 \mathrm{~h}$. After setting for $10 \mathrm{~h}$, the supernatant was poured out and centrifuged at $5000 \mathrm{rpm}$ for $5 \mathrm{~min}$. Finally, white powder was obtained by washing with anhydrous ethanol three times. The white powder is $\mathrm{TiO}_{2}$.

\section{Characterization}

Transmission electron microscopy (TEM) and high resolution transmission microscopy (HRTEM) were collected on a JEOL-2010 electron microscope. X-ray diffraction (XRD) analysis was employed on PANalytical $(\mathrm{Cu}-\mathrm{K} \alpha$ radiation, $\lambda=0.154051 \mathrm{~nm})$. Fourier transform infrared 
spectroscopy pattern (FTIR) was carried out on Nicolet 6700. X-ray photoelectron spectroscopy (XPS) analysis was conducted on Thermo Scientific Escalab 250Xi and element mapping by scanning electron microscopy (SEM) was conducted on Hitachi SU8220. Zeta potential and DLS measurements were carried out on Malvern Nano ZSE. UV-vis DRS and UPS measurement were conducted on and Thermo Fisher Scientific Escalab 250xi respectively. Steady-state photoluminescence (PL) emission spectrum and excited-state lifetime were conducted on Edinburgh Instruments FLS 1000.

\section{MB reduction test}

Quantities of titanium dioxide powder of $0.25 \mathrm{mg}, 2.5 \mathrm{mg}, 5.0 \mathrm{mg}, 25 \mathrm{mg}, 50 \mathrm{mg}$, and $100 \mathrm{mg}$ were added to $50 \mathrm{~mL} \mathrm{MB}$ solution at a concentration of $10 \mathrm{mg} \mathrm{L}^{-1}$, respectively. After $1 \mathrm{~h}$ of dark stirring, the mixture was stirred under a xenon lamp with a light intensity of $190 \mathrm{~mW} \cdot \mathrm{cm}^{-2}$ for $3 \mathrm{~h}$. Then, $5 \mathrm{~mL}$ of mixed liquid was taken every $0.5 \mathrm{~h}$, and the purified liquid was centrifuged to record the absorbance of $\mathrm{OD}_{664}$

\section{Isolation of chloroplast}

Lettuce leaves with variable treatment were homogenized in a buffer containing $0.40 \mathrm{M}$ sucrose, $10 \mathrm{mM} \mathrm{KCl}, 30 \mathrm{mM} \mathrm{Na}_{2} \mathrm{HPO}_{4}$, and $20 \mathrm{mM} \mathrm{KH}_{2} \mathrm{PO}_{4}$, and then filtered through four layers of cotton gauze. The filtrates were subsequently centrifuged at $1000 \mathrm{rpm}$ for $3 \mathrm{~min}$. Supernatant liquid in 
tube was centrifuged at $3000 \mathrm{rpm}$ for another $3 \mathrm{~min}$. Chloroplast were obtained from the residue in the bottom of the tube and spread in buffer solution.

\section{Hill reaction}

Concentrations of chloroplast suspension from lettuce leaves with variable treatment were measured by means of adding $0.10 \mathrm{~mL}$ chloroplast suspension into a $4.9 \mathrm{~mL}$ mixture of ethanol and acetone for measuring the absorbance at $650 \mathrm{~nm}$. $4.0 \mathrm{~mL}$ chloroplast suspension

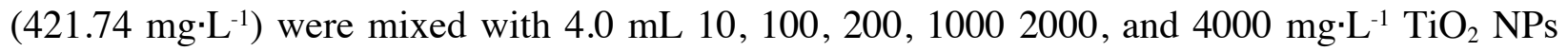
buffer dispersion for 2 h. $2.0 \mathrm{~mL}$ of $12 \mu \mathrm{M}$ DCPIP solution was added, subsequently. Illuminated under a xenon lamp with the intensity of $7.0 \mathrm{~mW} \mathrm{~cm}^{-2}$ for $5 \mathrm{~min}$, the absorbance spectrum was recorded at $600 \mathrm{~nm}$ every $1 \mathrm{~min}$.

\section{Ferricyanide reduction}

According to Chandra, ${ }^{2} 1.0 \mathrm{~mL}$ hybrid chloroplast suspension $\left(500 \mathrm{mg} \cdot \mathrm{L}^{-1}\right)$ was added to 2.0 $\mathrm{mM}$ ADP and $1.0 \mathrm{mM}$ ferricyanide. After $1 \mathrm{~min}$ of sunlight irradiance at an intensity of $73 \mathrm{~mW} \cdot \mathrm{cm}^{-2}, 2 \%$ trichloroacetic acid was added. Recorded The absorbance at $420 \mathrm{~nm}$ of the supernatant was recorded by $10 \mathrm{~min}$ of centrifuge at $8000 \mathrm{~g}$. 


\section{ATP measurement}

From hybrid chloroplast suspension, $1.0 \mathrm{~mL}$ was added to $2.0 \mathrm{mM}$ ADP. Following $1 \mathrm{~min}$ of sunlight irradiance at intensity of $73 \mathrm{~mW} \cdot \mathrm{cm}^{-2}$, an ATP Content Assay Kit was taken to measure the ATP content.

\section{$\mathrm{H}_{2}$ measurement}

$25 \mathrm{~mL}$ chloroplast suspension $\left(421.74 \mathrm{mg} \cdot \mathrm{L}^{-1}\right)$ was mixed with $25 \mathrm{~mL} 500 \mathrm{mg} \cdot \mathrm{L}^{-1} \mathrm{TiO}_{2} \mathrm{NPs}$ buffer dispersion for $2 \mathrm{~h}$. After 1 hour of illumination under a xenon lamp with a light intensity of $190 \mathrm{~mW} \cdot \mathrm{cm}^{-2}$, the hydrogen production was measured by TECHCOMP GC 7900.

\section{MDA measurement}

$4.0 \mathrm{~mL}$ chloroplast suspension $\left(421.74 \mathrm{mg} \cdot \mathrm{L}^{-1}\right.$ ) was mixed with $4.0 \mathrm{~mL} 1000 \mathrm{mg} \cdot \mathrm{L}^{-1} \mathrm{TiO}_{2}$ buffer solution. After $5 \mathrm{~min}$ of illuminating under a xenon lamp with a light intensity of $7.0 \mathrm{~mW} \cdot \mathrm{cm}^{-2}$, it was centrifuged at $3000 \mathrm{rpm}$ for $3 \mathrm{~min}$, then $0.05 \mathrm{M}$ phosphate buffer $\left(\mathrm{Na}_{2} \mathrm{HPO}_{4}, \mathrm{NaH}_{2} \mathrm{PO}_{4}\right)$ were used to wash away the sucrose phosphate buffer three times. A MDA Content Assay Kit was taken to measure the MDA content.

\section{SOD measurement}

The SOD activity was measured by a SOD Content Assay Kit. 


\section{Spraying on lettuce leaves}

Lettuce seeding was Italian Lettuce purchased from Guangdong Academy of Agricultural Sciences in China. When the seedlings were grown to three leaves, they were transplanted to the hydroponic rack. After 10 days of transplanting, 5.0, 50, and $100 \mathrm{mg} \cdot \mathrm{L}^{-1}$ of as-prepared $\mathrm{TiO}_{2} \mathrm{NP}$ dispersion solution was sprayed on the leaves and treated every 5 days. A one-way analysis of variance (ANOVA) was used to analyse the differences.

\section{Sample preparation for ICP-MS}

The lettuce leaves were washed with pure water three times to clean $\mathrm{TiO}_{2} \mathrm{NP}$ covering on the surface of the leaves. After drying, $0.50 \mathrm{~g}$ dry sample was added to $5 \mathrm{~mL} \mathrm{HCl}$ and mixed with 2.0 $\mathrm{mL} \mathrm{H}_{2} \mathrm{O}_{2}$, placed into a microwave digestion system at $180{ }^{\circ} \mathrm{C}$ for $1 \mathrm{~h}$.

\section{Zeta potential and DLS measurement}

The Zeta potential of $\mathrm{TiO}_{2}, \mathrm{CLP}$ and the hydrate particle size of $\mathrm{TiO}_{2}$ were measured by Molvern Zetasizer Nano ZS90. 


\section{Supplementary figures and tables}
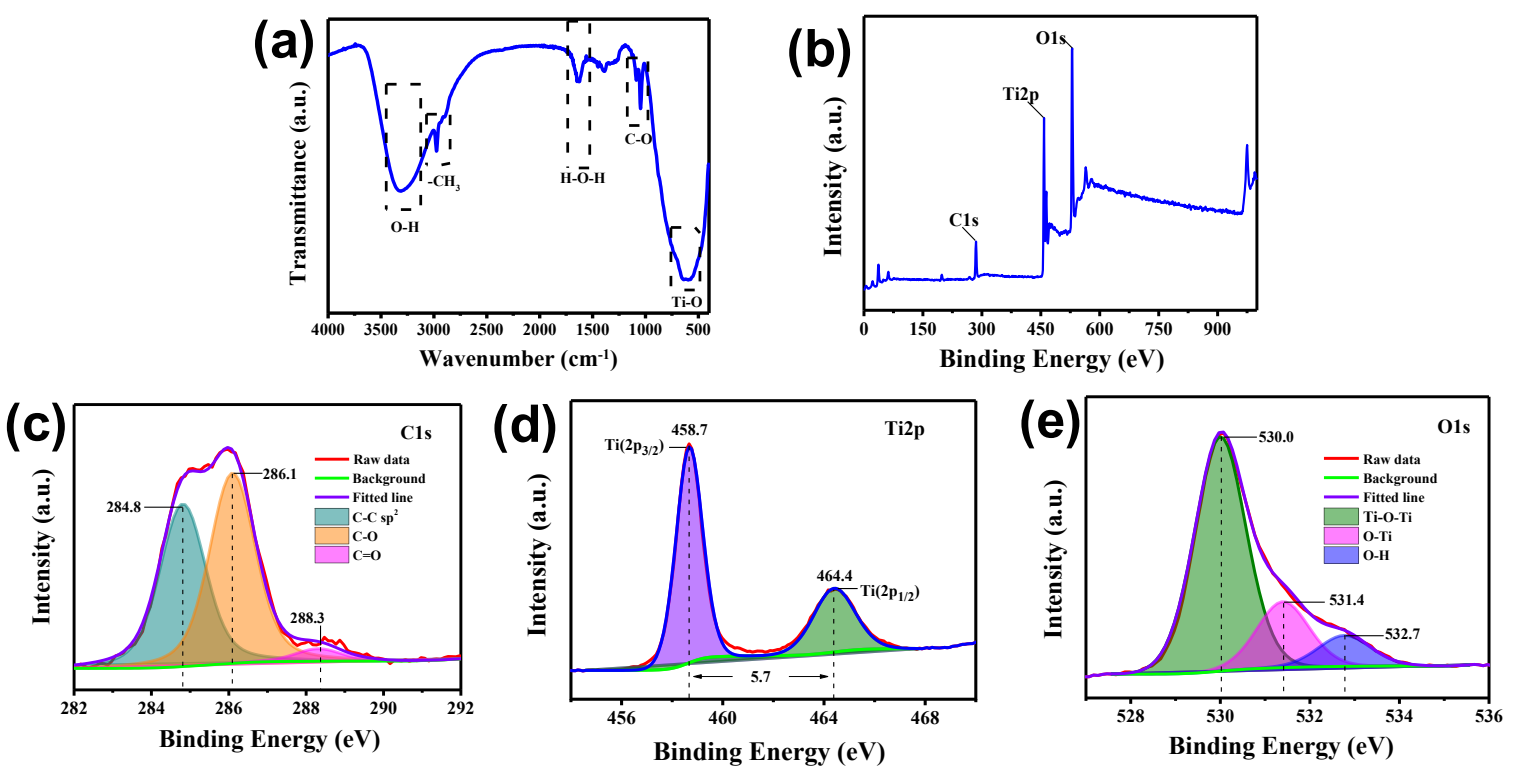

Figure S1 (a) FTIR image of $\mathrm{TiO}_{2}$. (b) XPS image of $\mathrm{TiO}_{2}$. (c-d) XPS peak separation images of $\mathrm{C} 1 \mathrm{~s}$, $\mathrm{Ti}(2 \mathrm{p}$ ), and $\mathrm{O} 1 \mathrm{~s}$.

Table S1 DLS data of $\mathrm{TiO}_{2}$

\begin{tabular}{lllll}
\hline Sample & PDI & Size $($ d.nm $)$ & Volume $(\%)$ & St Dev. \\
\hline 1 & 0.249 & 13.04 & 100 & 6.754 \\
2 & 0.264 & 10.68 & 100 & 6.485 \\
3 & 0.262 & 11.72 & 100 & 6.823 \\
4 & 0.247 & 9.738 & 100 & 6.578 \\
Average & 0.255 & 11.2945 & 100 & \\
\hline
\end{tabular}




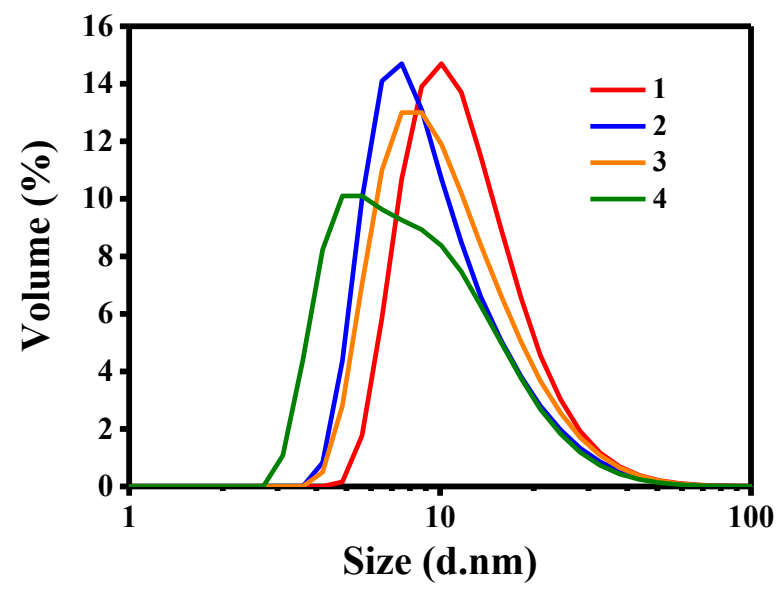

Figure S2 Volume/Size distribution of $\mathrm{TiO}_{2} \mathrm{NPs}(1,2,3,4$ represent the repetition times)
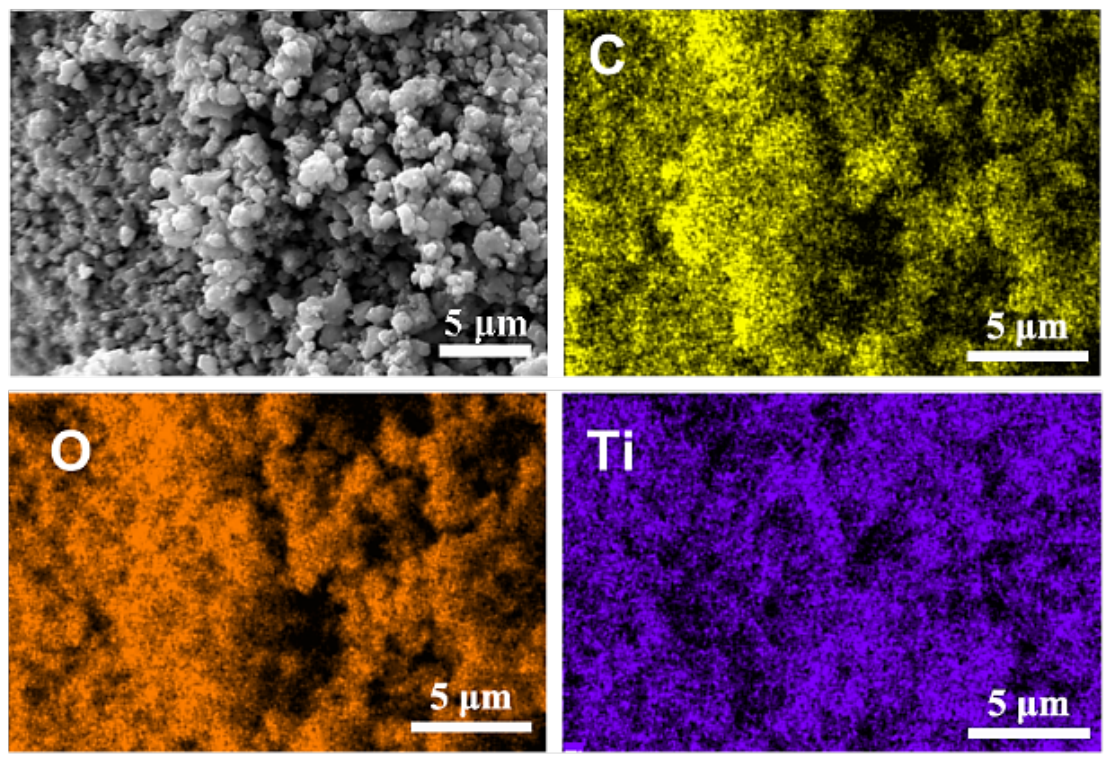

Figure S3 Element mapping of as-prepared $\mathrm{TiO}_{2}$ powder. 


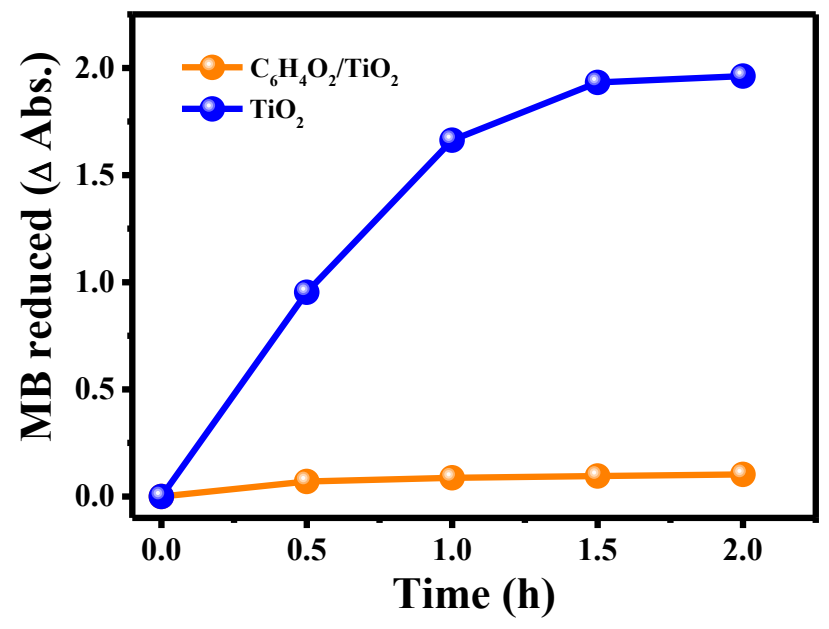

Figure $\mathrm{S} 4 \mathrm{MB}$ reduction by $\mathrm{TiO}_{2}$ and with $\mathrm{C}_{6} \mathrm{H}_{4} \mathrm{O}_{2}$ present. (The $\mathrm{MB}$ reduction experiments were carried out under a xenon lamp with the intensity of $190 \mathrm{~mW} \cdot \mathrm{cm}^{-2}$, expressed as absolute difference in absorbance.)

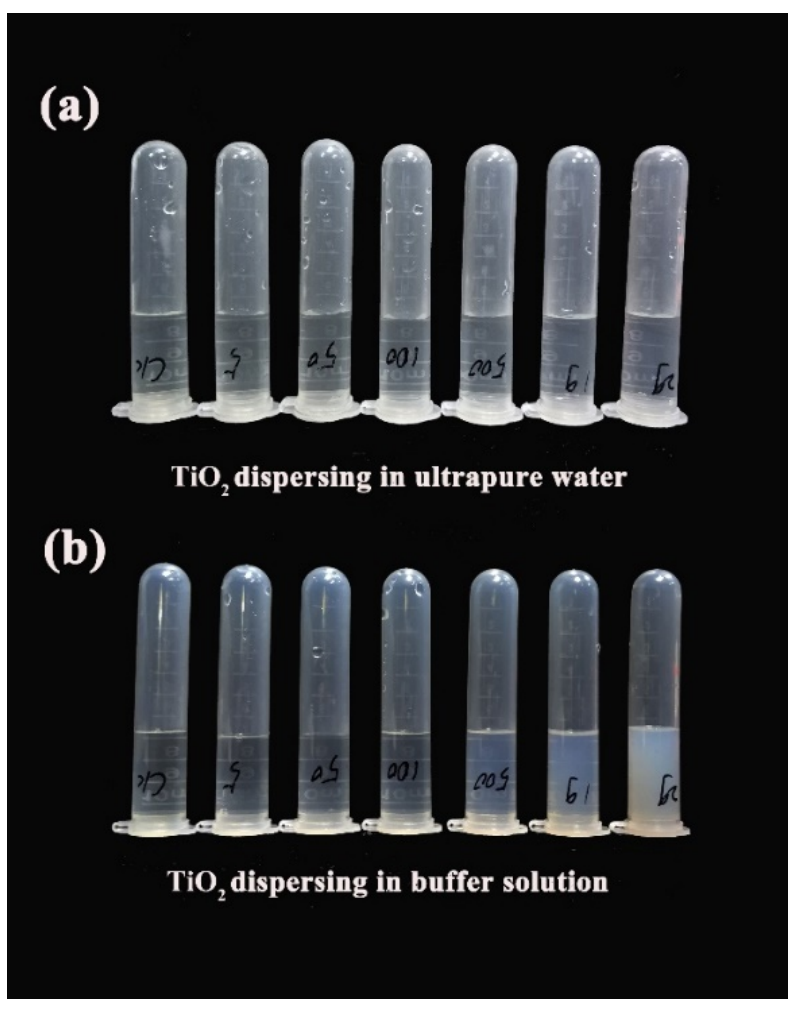

Figure S5 (a) Variable concentrations of $\mathrm{TiO}_{2}$ dispersed in ultrapure water. (b) Variable concentrations of $\mathrm{TiO}_{2}$ dispersed in buffer solution. 


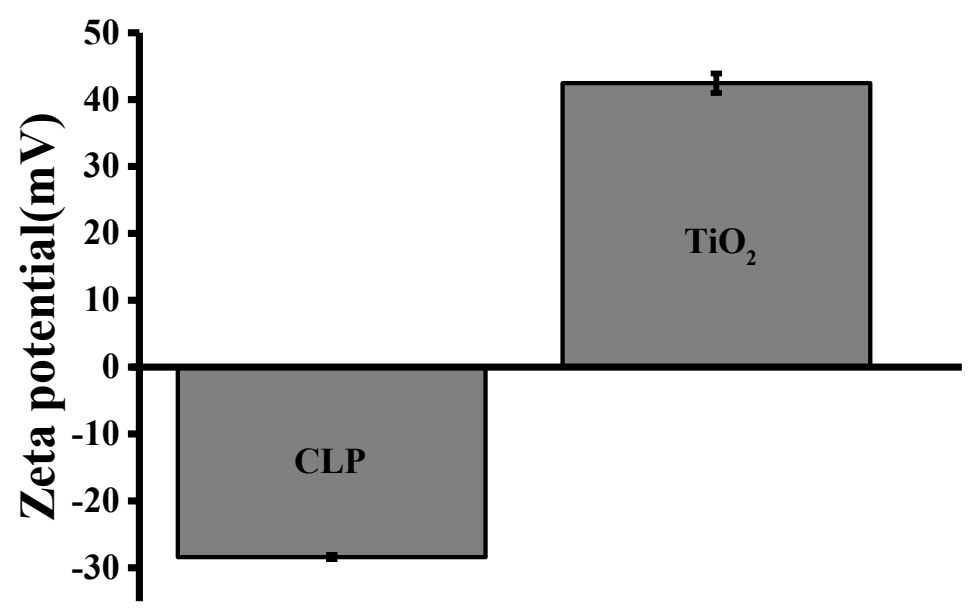

Figure S6 Zeta potential of $\mathrm{TiO}_{2}$ and CLP.
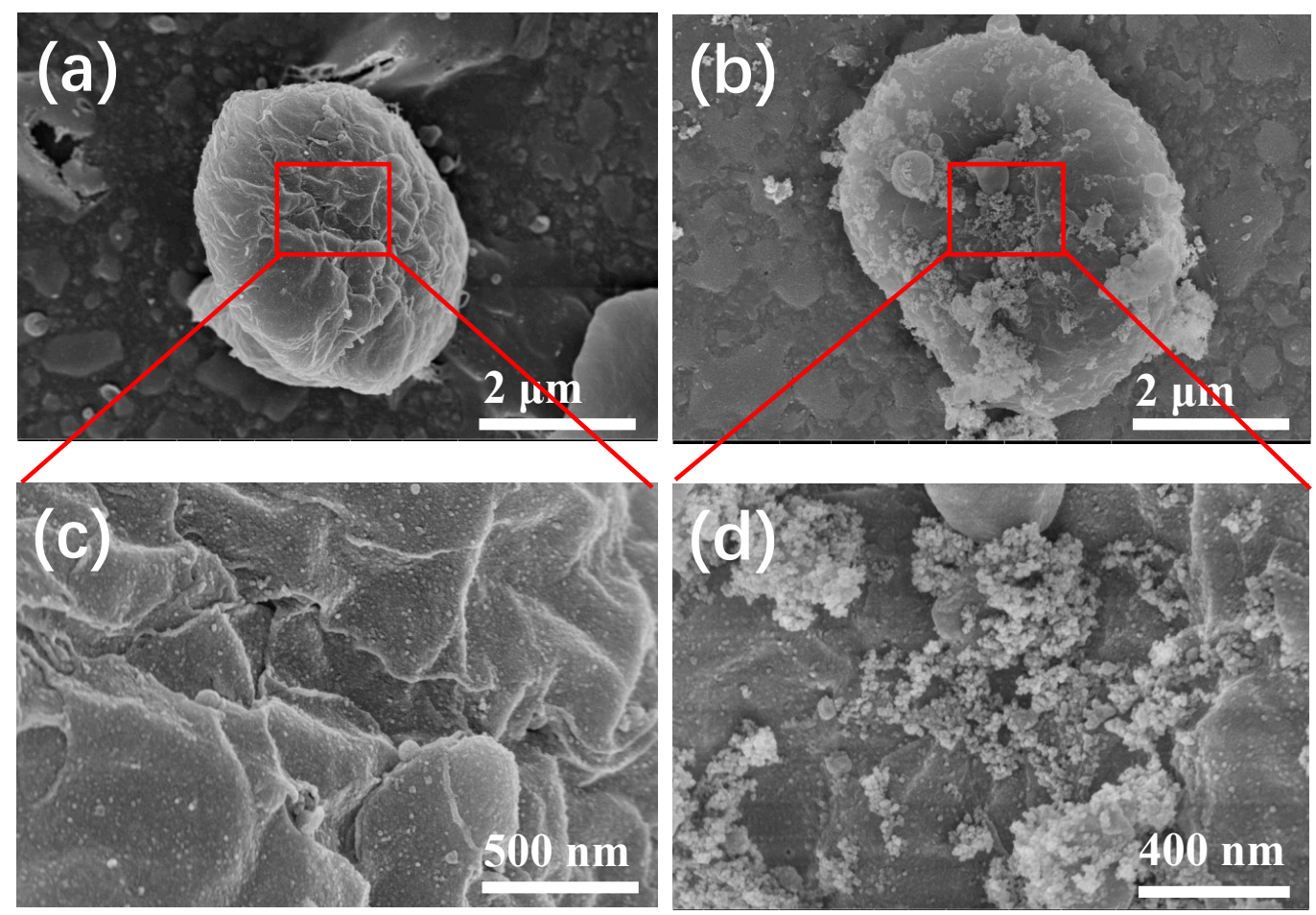

Figure S7 (a) FESEM image of pure CLP; (b) FESEM image of $\mathrm{TiO}_{2} / \mathrm{CLP}$; (c) Enlarged FESEM image of pure CLP; (d) Enlarged FESEM image of $\mathrm{TiO}_{2}$ NPs distributed on CLP surface. 


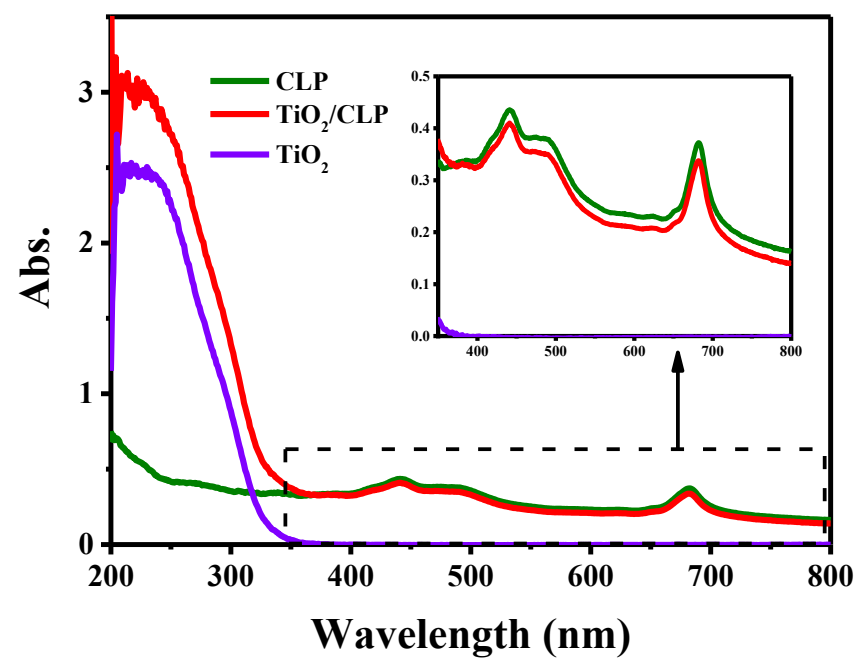

Figure S8 UV-vis absorption spectrum of $\mathrm{TiO}_{2}$, chloroplast, and $\mathrm{TiO}_{2} / \mathrm{CLP}$.

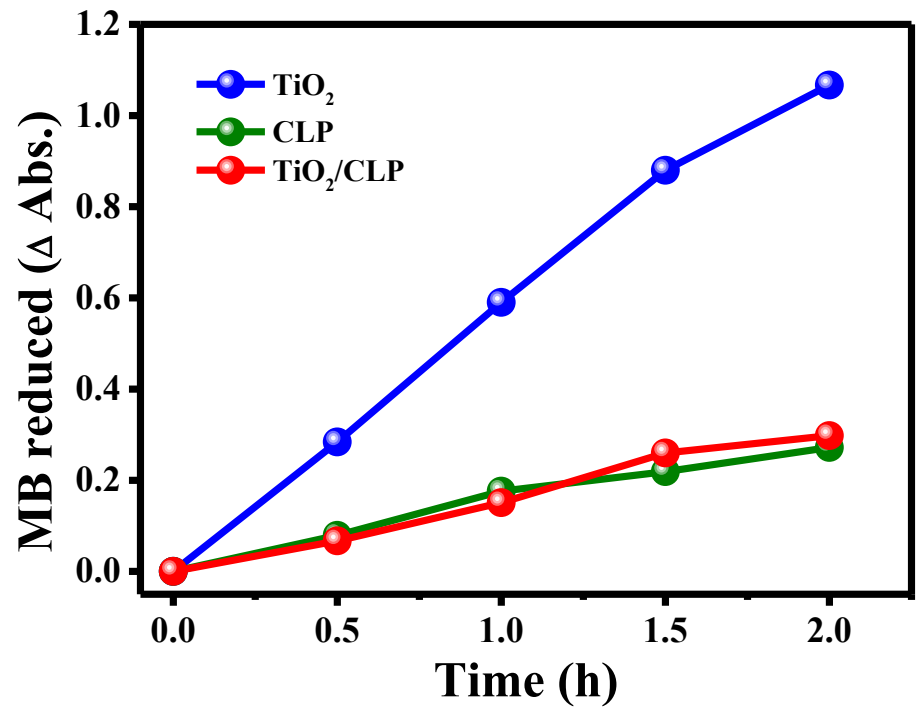

Figure S9 MB reduction by $\mathrm{TiO}_{2}$ and $\mathrm{TiO}_{2} / \mathrm{CLP}$ in buffer solution. (The $\mathrm{MB}$ reduction experiments were carried out under a xenon lamp with the intensity of $190 \mathrm{~mW} \cdot \mathrm{cm}^{-2}$, expressed as absolute difference in absorbance.) 

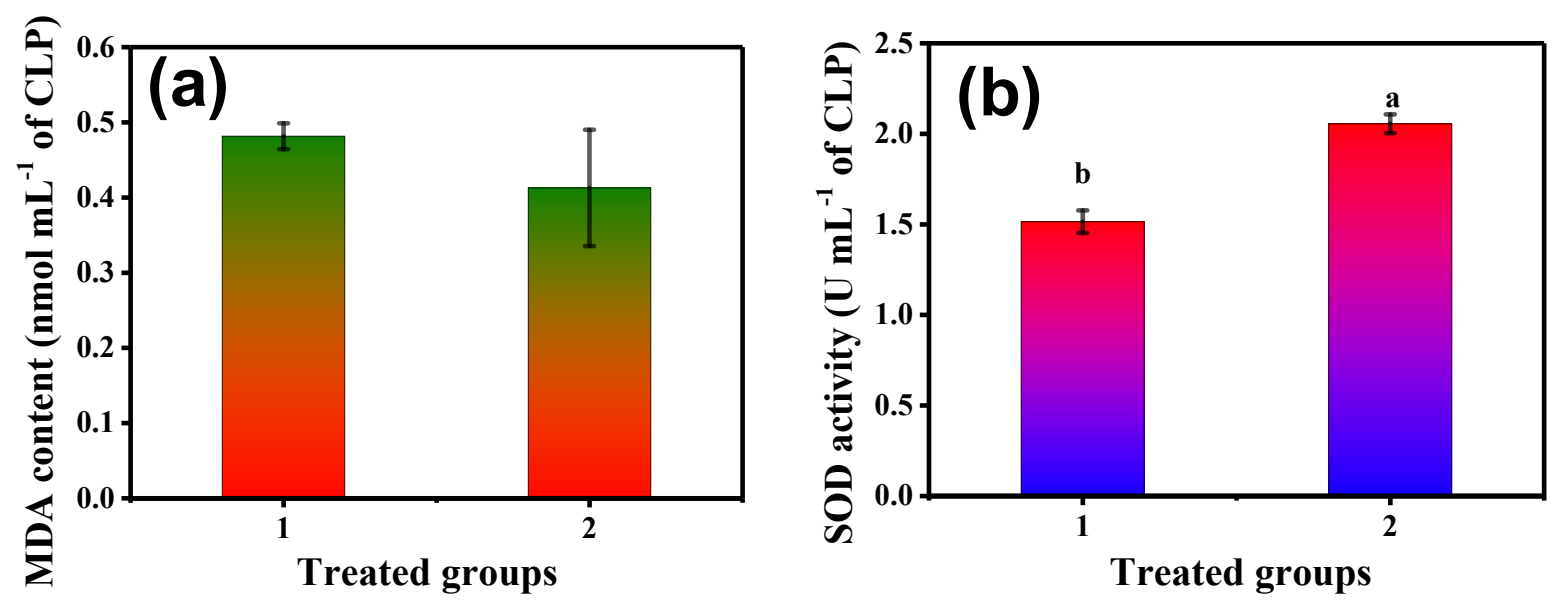

Figure S10 (a) MDA content of CLP and $\mathrm{TiO}_{2} / \mathrm{CLP}$ after illuminating. (b)SOD activity of CLP and $\mathrm{TiO}_{2} / \mathrm{CLP}$ after illuminating. (The illumination was under a xenon lamp with the light intensity of $7.0 \mathrm{~mW} \mathrm{~cm}^{-2}$; "1" represents the CLPs and "2" represents the $\mathrm{TiO}_{2} / \mathrm{CLPs}$. $\mathrm{P}<0.05$, "a" represents the highest grade number while "b" represents the lower grade number, the different letters mean they have significant difference.)

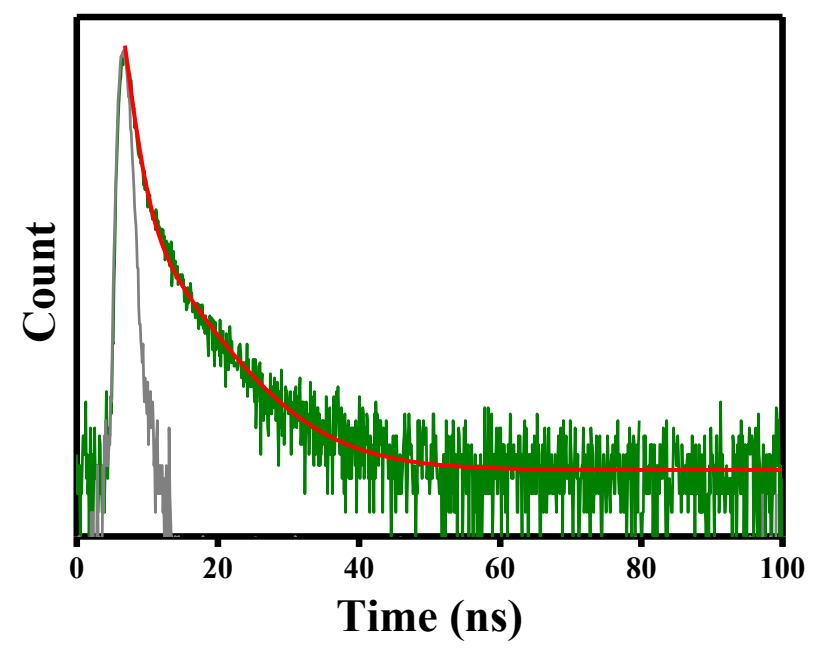

Figure S11 TRPL decay profiles of CLP monitored at $450 \mathrm{~nm}$ emission. 
Table S2 Multi-exponential fitting of $\mathrm{TiO}_{2}$ and $\mathrm{TiO}_{2} / \mathrm{CLP}$

\begin{tabular}{lllllll}
\hline Sample & $\tau_{1}$ & $\mathrm{~A}_{1}$ & $\tau_{2}$ & $\mathrm{~A}_{2}$ & $\tau$ & $\chi^{2}$ \\
\hline $\mathrm{TiO}_{2}$ & 2.14126 & 11043.79959 & 10.65794 & 287.58052 & 3.118465477 & 0.99019 \\
$\mathrm{TiO}_{2} / \mathrm{CLP}$ & 1.23236 & 104668.5925 & 7.65501 & 313.39647 & 1.349632711 & 0.99404 \\
$\mathrm{CLP}$ & 1.31985 & 161119.68573 & 7.58672 & 371.58545 & 1.401841857 & 0.99261 \\
\hline
\end{tabular}

Computational formula: $\tau=\left(\mathrm{A}_{1} \tau_{1}^{2}+\mathrm{A}_{2} \tau_{2}^{2}\right) /\left(\mathrm{A}_{1} \tau_{1}+\mathrm{A}_{2} \tau_{2}\right)$

\section{REFERENCES}

(1) Liu, X.; Chen, Y.; Rao, S. H.; Pang, G. S. One Step Preparation of Highly Dispersed $\mathrm{TiO}_{2}$ Nanoparticles. Chem. Res. Chinese U. 2015, 31, 688-692.

DOI: $10.1007 / \mathrm{s} 40242-015-5300-2$

(2) Chandra, S.; Pradhan, S.; Mitra, S.; Patra, P.; Bhattacharya, A.; Pramanik, P.; Goswami, A. High throughput Electron Transfer from Carbon Dots to Chloroplast: A Rationale of Enhanced Photosynthesis. Nanoscale 2014, 6, 3647-3655.

DOI: $10.1039 / \mathrm{c} 3 \mathrm{nr} 06079 \mathrm{a}$ 